\title{
Binding and invasion of HeLa and MRC-5 cells by Streptococcus agalactiae
}

\author{
Gregory J. Tyrrell, ${ }^{1,2,3}$ Alexander Kennedy, ${ }^{1,2}$ Sandra E. Shokoples ${ }^{1}$ \\ and Richard K. Sherburne ${ }^{3}$
}

Author for correspondence: Gregory J. Tyrrell. Tel: +1 780407 8949. Fax: +1 7804073864.
e-mail: g.tyrrell@provlab.ab.ca

1 National Centre for Streptococcus, Provincial Laboratory for Public Health (Microbiology), Edmonton, Alberta, Canada T6G 2J2

2,3 Department of Laboratory Medicine and Pathology2 and Department of Medical Microbiology and Immunology3, University of Alberta, Edmonton, Alberta, Canada T6G 2J2
The interactions of group B streptococci (GBS) with HeLa cells (an epithelial cell line) and MRC-5 cells (a fibroblastic cell line) were explored. A host-cell invasion assay using GBS strains from all serotypes revealed that GBS invaded HeLa cells to a greater extent than MRC-5 cells. One strain, a serotype $V$ (NCS13), was highly invasive against HeLa cells. All strains were poorly invasive against MRC- 5 cells. Further characterization of the binding of NCS13 to HeLa and MRC-5 cell surfaces showed that the lack of recoverable c.f.u. from MRC- 5 cells was due to a lack of binding of NCS13 to the MRC-5 cell surface in comparison to HeLa cells. Although fibronectin had been reported to bind to GBS, fibronectin assays showed 2-7-fold more fibronectin on the MRC-5 cell surface in comparison to HeLa cells, suggesting that other extracellular matrix proteins besides fibronectin may be involved in GBS binding. Scanning electron microscopy of NCS13 and HeLa cells over a $6 \mathrm{~h}$ time period showed increased numbers of NCS13 on the HeLa cell surface over time until cell death at 6 h. Direct contact of the HeLa cell surface by NCS13 was found to be necessary for cell death to occur. Further scanning electron microscopy studies found that, once GBS are bound to the HeLa cell surface, HeLa cell microvilli entwine the bacteria, which then enter the HeLa cell in a polar fashion. Cytoskeletal actin is involved, as this process is disrupted by cytochalasin $D$, and recruitment of actin is visible at the site of adherent chains of GBS. Also, the host-cell signalling enzyme, PI 3-kinase, is involved in the GBS internalization process, since the PI 3-kinase inhibitor, wortmannin, inhibited NCS13 invasion of HeLa cells in a dose-dependent manner.

Keywords: actin, streptococci, phosphatidylinositol 3-kinase, scanning electron microscopy

\section{INTRODUCTION}

Group B streptococci (GBS) colonize the genital tract of $15-40 \%$ of pregnant women, with approximately $50 \%$ of infants born to these women becoming colonized during delivery (Allardice et al., 1982; Anthony et al., 1981; Campbell et al., 2000; Schuchat et al., 1990, 1994). About $1-2 \%$ of colonized infants develop severe earlyonset GBS infections. These include pneumonia, sepsis and/or meningitis. Estimates have placed this rate in North America at 0.2-5 infants per 1000 live births

Abbreviations: GBS, group B streptococci; NCS, National Centre for Streptococcus; SBA, sheep blood agar; SEM, scanning electron microscopy; TEM, transmission electron microscopy.
(Allardice et al., 1982; Anthony et al., 1981; Campbell et al., 2000; Schuchat et al., 1990, 1994). In the case of early-onset disease of the neonate, it is thought that the infant can directly inhale the organism during birth, which then spreads within the respiratory tract and invades the bloodstream and eventually the meninges. In the mother, GBS are also associated with post-partum infections that can lead to bacteraemia and endocarditis, which probably result from colonization of the female genital tract. Invasive GBS disease is also a major problem in nonpregnant adults such as the elderly and those with chronic illness, resulting in a wide spectrum of invasive disease which includes mild skin infections to more serious bacteraemia and meningitis (Edwards \& Baker, 1995; Farley et al., 1993; Schuchat et al., 1990; Tyrrell et al., 2000). 
The mechanism(s) used by GBS to cause invasive disease in the host are not completely understood, but it is clear that GBS are able to invade host cells. This has been demonstrated for HEp-2 cells, HeLa cells, A549 cells, MDCK cells, human brain microvascular endothelial cells, etc. (Gibson et al., 1993; Hulse et al., 1993; Kallman \& Kihlstrom, 1997; Lalonde et al., 2000; Nizet et al., 1997; Rubens et al., 1991, 1992; Tamura \& Rubens, 1994; Valentin-Weigand et al., 1996). While GBS have been shown to be invasive against a wide variety of host cells, the events that occur upon the adherence and internalization have not been fully elucidated.

A number of host-cell structures have been suggested as receptors for GBS. These include laminin, cytokeratins, fibronectin, fibrinogen, etc. (Cheng et al., 2002; Spellerberg et al., 1999, 2002; Tamura \& Nittayajarn, 2000; Tamura \& Rubens, 1995). Most recently, Beckmann et al. (2002) and Cheng et al. (2002) have shown that the C5a peptidase in GBS plays a role in binding to fibronectin and invasion of A549 and HEp-2 cells. Other recent work by Tamura et al. (2002) demonstrated that the GBS gene, $g \ln Q$, is required for GBS adherence to immobilized fibronectin and also plays a role in binding and invasion of A549 cells. However, while these components (laminin, cytokeratin, fibronectin, etc.) have been shown to bind or be involved in the binding and invasion of host cells by GBS, whether they function as the main GBS receptor in the host cell or whether a main GBS receptor exists is not completely clear.

In addition, previous investigators have found that invasion requires actin microfilaments, since this invasion is disrupted by cytochalasin $\mathrm{D}$, an inhibitor of polymerization of actin (Gibson et al., 1993; Nizet et al., 1997; Rubens et al., 1992; Valentin-Weigand et al., 1996, 1997). Further work has shown that exploitation of eukaryotic signal-transduction pathways seems to be occurring as GBS invasion is inhibited by protein kinase inhibitors staurosporine and genistein. This has suggested that GBS uptake occurs via a multicomponent pathway for which very few components have been identified.

In the following study, we describe experiments examining the physical interaction of GBS with HeLa and MRC-5 cell surfaces and begin an analysis of the mechanism of internalization with respect to the involvement of the actin cytoskeleton and phosphatidylinositol 3-kinase.

\section{METHODS}

Bacterial strains and cell lines. The GBS isolates used in this study are part of the National Centre for Streptococcus (NCS) collection of clinical isolates sent to the NCS for further characterization. The cell lines HeLa 229 (ATCC CCL-2.1) and MRC-5 (ATCC CCL-171) were obtained from the American Type Culture Collection. These cell lines were grown in OPTI-MEM reduced-serum medium containing $4 \%$ fetal bovine serum (Gibco-BRL).
GBS invasion assay. The assay was performed as previously described, with some changes (Rubens et al., 1992). Briefly, GBS were passaged once on sheep blood agar (SBA) and then passaged in Todd-Hewitt broth overnight. A $0.5 \mathrm{McF}$ arland in PBS was made and diluted $1: 100$. One hundred microlitres of this suspension (approx. $1.5 \times 10^{5}$ bacteria) was applied to confluent cell monolayers in $1 \mathrm{ml}$ OPTI-MEM plus $4 \%$ fetal bovine serum contained in 24-well Falcon tissue culture plates (Becton Dickinson). The cell monolayers and GBS were incubated at $37^{\circ} \mathrm{C}$ for the period of time specified depending on the experiment. The monolayers were washed three times with PBS and then incubated with medium containing $5 \mu \mathrm{g}$ penicillin $\mathrm{ml}^{-1}$ and $100 \mu \mathrm{g}$ gentamicin $\mathrm{ml}^{-1}$ for $2 \mathrm{~h}$. After this incubation, the monolayers were again washed three times with PBS. The tissue culture cells were then trypsinized and plated onto SBA (output) and incubated overnight at $37^{\circ} \mathrm{C}$. Also, a further $1: 100$ dilution was made of the original input, and $100 \mu \mathrm{l}$ of this was plated onto SBA, incubated overnight at $37^{\circ} \mathrm{C}$ and used as the input count. After overnight incubation, colonies were counted (both input and output) to determine the number of GBS that had invaded the monolayer in relation to the number of GBS added to the monolayer.

Fluorescent microscopy. To visualize GBS bound to eukaryotic cells, shell vials containing HeLa or MRC-5 cells were grown to confluency. One hundred microlitres of a 1:10 dilution of a 0.5 McFarland of GBS (overnight culture) (approx. $1.5 \times 10^{6}$ bacteria) was added to the shell vial and then incubated at $37^{\circ} \mathrm{C}$ for $2 \mathrm{~h}$. The cells were washed three times with PBS and fixed with $3 \%$ formaldehyde for $30 \mathrm{~min}$ followed by another wash three times with PBS. Rabbit Streptococcus antiserum group B (Difco) was then added, followed by a secondary rhodamine-conjugated goat antirabbit IgG Fc antibody (Chemicon). The specimens were then examined by confocal microscopy using a Zeiss 510 NLO (Carl Zeiss) laser-scanning microscope. For fibronectin visualization, the HeLa and MRC-5 cells were grown to confluency on $12 \mathrm{~mm}$ coverslips, fixed with $3 \%$ formaldehyde and stained with rabbit anti-human fibronectin antibody (Sigma) diluted 1:400. This was then washed with PBS, and anti-rabbit FITC conjugate was added (1:80). The coverslips were washed with PBS, mounted and examined using fluorescent microscopy. For actin recruitment visualization, HeLa cells were permeabilized after the $3 \%$ formaldehyde step with $0 \cdot 1 \%$ Triton X-100. The cells were then stained with FITC phalloidin (Sigma) as previously described (Knutton et al., 1989).

Comparison of levels of fibronectin on HeLa and MRC-5 cells using an EIA. MRC-5 or HeLa cells were grown to confluency in the wells of a 96-well tissue culture plate (Corning Costar). The media were removed from the cells, and the cells were fixed with $3 \%$ formaldehyde. A dilution of 1:400 of antifibronectin polyclonal antibody (Sigma) was made in $50 \mathrm{mM}$ Tris-buffered saline. Two hundred microlitres of antibody was added to the wells containing each cell line in triplicate. The plate was incubated at $37^{\circ} \mathrm{C}$ for $1 \mathrm{~h}$ then washed with $10 \mathrm{mM}$ PBS/Tween three times. Two hundred microlitres of 1:30000 anti-rabbit IgG conjugated with alkaline phosphatase (Sigma) was then added to the wells. The plate was incubated at $37^{\circ} \mathrm{C}$ for $1 \mathrm{~h}$ and then washed with $10 \mathrm{mM}$ PBS/Tween three times. Two hundred microlitres of pNPP (alkaline phosphatase yellow) was then added to the wells and the plate incubated for $1 \mathrm{~h}$ at room temperature. Absorbance was read at $405 \mathrm{~nm}$ blanked against triplicate wells containing substrate and cells only.

Cytochalasin D treatment. For both pre- and post-GBS infection, cytochalasin D (Sigma-Aldrich Canada) was added 
to HeLa cell monolayers at a concentration of $1 \cdot 0 \mu \mathrm{g} \mathrm{ml}^{-1}$. For pretreatment, the cytochalasin $\mathrm{D}$ was added $1 \mathrm{~h}$ prior to the addition of GBS. GBS was allowed to interact with the HeLa cell monolayer for $2 \mathrm{~h}$, after which the monolayer was washed three times with PBS and either treated with trypsin and plated onto SBA or prepared for scanning electron microscopy (SEM). For post-treatment, GBS were allowed to infect HeLa cells for $1 \mathrm{~h}$ before treatment with cytochalasin D. After the $1 \mathrm{~h}$ GBS exposure, the HeLa cells were treated with cytochalasin D for a further $1 \mathrm{~h}$. The monolayer was then washed three times with PBS and prepared for SEM.

SEM and transmission electron microscopy (TEM). For SEM, identical pre- and post-cytochalasin D treatment of HeLa cells exposed to GBS was carried out as described in the previous section with the exception that the monolayers were grown on 13-mm-diameter sterile thermanox plastic cell-culture coverslips (Nalge Nunc). After exposure to GBS with or without cytochalasin D treatment, the coverslips were prepared for SEM or TEM. For SEM, the coverslips were fixed with freshly prepared $2 \%(\mathrm{v} / \mathrm{v})$ glutaraldehyde, in phosphate buffer, $\mathrm{pH} 7 \cdot 3$, overnight at $4{ }^{\circ} \mathrm{C}$. The samples were then washed three times in phosphate buffer and further fixed in $1 \%(\mathrm{w} / \mathrm{v})$ osmium tetroxide for $3 \mathrm{~h}$, washed in phosphate buffer, then dehydrated in a graded series of ethanol at room temperature and critical-point-dried (Balzers critical point dryer \#CPD 030). The coverslips were mounted on standard Cambridge SEM stubs, sputter-coated lightly with gold and examined in a Hitachi S 4100 field emission scanning electron microscope.

For TEM, after fixation and dehydration in a graded series of alcohol, the coverslips were transferred through two changes of propylene for $30 \mathrm{~min}$ each time. Samples were then transferred to a 1:1 mixture of propylene oxide and LX 112 resin (Ladd Research Industries) and left uncapped for $24 \mathrm{~h}$ at room temperature. On the following day, the samples were transferred to pure LX 112 for $1 \mathrm{~h}$. Fresh LX 112 was placed onto the coverslips, and micro-centrifuge tubes filled with LX 112 were inverted on top of the coverslips. The samples were then cured for $24 \mathrm{~h}$ at $60{ }^{\circ} \mathrm{C}$. Sections were then cut using a Reichert-Jung Ultracut and placed on $3 \mathrm{~mm}, 200 \mathrm{mesh}$ Formvar-coated copper grids. These were stained with $5 \%$ uranyl acetate for $10 \mathrm{~min}$ and lead citrate for $6 \mathrm{~min}$. Images were recorded on a Kodak \#4489 electron microscope film using a Hitachi model H7000 transmission electron microscope.

Analysis of GBS-HeLa cell interactions over a $6 \mathrm{~h}$ period. To analyse the effect of GBS on HeLa cells over a $6 \mathrm{~h}$ period, HeLa cell monolayers were grown on thermanox coverslips in a 24well transwell plate containing $1 \mathrm{ml}$ medium per well. After $24 \mathrm{~h}$, the HeLa cells reached confluency, and a 1:10 dilution of a $0.5 \mathrm{McF}$ arland suspension of an overnight culture of GBS grown in Todd-Hewitt broth was added to the monolayers. At 1, 2, 3, 4, 5 and 6 h time points, coverslips were removed and washed three times with PBS. The coverslips were then prepared for SEM observation.

To determine whether GBS physical contact of the HeLa cells was required to cause HeLa cell destruction, HeLa cells were prepared by the same process as described above to the point where GBS was to be added. At this point, a $0 \cdot 4-\mu \mathrm{m}$-pore-size transwell membrane was placed over the top as needed (Corning Costar). A 0.5 McFarland of an overnight culture of GBS was made, and $100 \mu \mathrm{l}$ of this was added directly to the HeLa cell monolayer or the top of the transwell membrane. After a $6 \mathrm{~h}$ incubation at $35^{\circ} \mathrm{C}$, the monolayer was washed three times with PBS and then fixed with formaldehyde for 30 min. Monolayers were then washed three times with PBS and stained for $20 \mathrm{~s}$ with crystal violet. The coverslips were then washed three times with PBS and examined.

Inhibition of GBS invasion by wortmannin. HeLa cells were grown to $80-95 \%$ confluency in a 24 tissue culture plate. Wortmannin was added to the HeLa cells in concentrations ranging from $2 \mathrm{nM}$ to $2 \mu \mathrm{M}$ in triplicate and incubated for $30 \mathrm{~min}$ at $37^{\circ} \mathrm{C}$. GBS were then added and the plate incubated for $2 \mathrm{~h}$ at $37^{\circ} \mathrm{C}$. After $2 \mathrm{~h}$, the cells were washed with PBS, and medium containing the appropriate concentration of wortmannin, penicillin and gentamicin was added. After a further $2 \mathrm{~h}$ incubation at $37^{\circ} \mathrm{C}$, the cells were washed with PBS, and $0 \cdot 25 \%$ trypsin was added to each well. The plate was incubated at $37^{\circ} \mathrm{C}$ until the cells were detached. The contents of each well were plated onto SBA, incubated overnight and c.f.u. determined on the following day.

\section{RESULTS AND DISCUSSION}

\section{Selection of an invasive strain of GBS against HeLa cells}

For GBS to reach their full pathogenic potential, the bacteria must first breach a number of different cell types, including epithelial cells, to gain access to the bloodstream and, in some cases, cerebrospinal fluid. Previous investigators have found that GBS strains vary in their ability to invade epithelial cells (Rubens et al., 1992; Valentin-Weigand \& Chhatwal, 1995). The variability in the invasive phenotype made it necessary to assay a number of GBS strains to select a strain invasive against HeLa cells. We chose HeLa cells as our model system, as GBS invade this cell line extremely well in comparison to other cell lines (Lalonde et al., 2000). Eighteen strains were assayed for their invasive abilities. They were chosen to include all serotypes as well as being isolated from patients of varying ages (Table 1). The most invasive isolate against HeLa cells was a serotype V, designated NCS13 (Table 1). This bacterium was isolated from a soft tissue wound of an 82-year-old male.

Interestingly, the five least invasive strains against HeLa cells (NCS1, NCS3, NCS5, NCS6 and NCS10) were from infants with invasive group B streptococcal neonatal disease. Since NCS13 was the most invasive of the 18 strains assayed, it was selected for further study.

\section{Binding and invasion of NCS13 against HeLa cells}

To quantitate the invasive ability of NCS13 against HeLa cells, a standard invasion assay was performed. This assay involves the use of antibiotics to kill any noninvasive bacteria after a defined incubation period, and the invasive bacteria are quantified as c.f.u. The assay showed that the initial invasion level was low but rapidly changed, with over $2 \%$ of the initial inoculum becoming intracellular after $180 \mathrm{~min}$ (Fig. 1).

The finding that NCS13 continued to invade HeLa cells up to $3 \mathrm{~h}$ prompted us to observe the interaction of NCS13 with HeLa cells over a longer period of time. This was done by examining coverslips at $1 \mathrm{~h}$ intervals over a $6 \mathrm{~h}$ time period by SEM. Coverslips of confluent 
Table 1. Number of intracellular GBS in HeLa and MRC-5 cells, site of isolation and age of patient

\begin{tabular}{|c|c|c|c|c|c|c|}
\hline Isolate & Serotype & $\begin{array}{c}\text { HeLa } \\
\text { mean c.f.u. }(\mathrm{SD})\end{array}$ & $\begin{array}{c}\text { MRC-5 } \\
\text { mean c.f.u. (SD) }\end{array}$ & $\begin{array}{c}\text { Site of } \\
\text { isolation* }\end{array}$ & $\begin{array}{l}\text { Age of } \\
\text { patient }\end{array}$ & Reference \\
\hline NCS1 & Ia & $24(8)$ & $148(102)$ & Blood & 5 days & This study \\
\hline NCS2 & Ia & $30(16)$ & $182(133)$ & Blood & 50 years & This study \\
\hline NCS3 & Ia & $0(0)$ & $0(0)$ & Blood & 3 days & This study \\
\hline NCS4 & $\mathrm{Ib}$ & $127(42)$ & $50(13)$ & CSF & 2 months & This study \\
\hline NCS5 & $\mathrm{Ib}$ & $0(0)$ & $7(5)$ & Blood & 20 days & This study \\
\hline NCS6 & II & $162(64)$ & $90(36)$ & Blood & 10 days & This study \\
\hline NCS7 & II & $313(65)$ & $137(78)$ & Blood & 55 years & This study \\
\hline NCS8 & III & $103(85)$ & $156(55)$ & Blood & 52 years & This study \\
\hline NCS9 & III & 989 (356) & $128(99)$ & Blood & 44 years & This study \\
\hline NCS10 & III & $1(1)$ & $0(0)$ & CSF & 13 days & This study \\
\hline NCS11 & IV & 737 (134) & $348(195)$ & Blood & 61 years & This study \\
\hline NCS12 & IV & $1863(551)$ & $89(72)$ & Blood & 66 years & This study \\
\hline NCS13 & $\mathrm{V}$ & $3248(1548)$ & $150(79)$ & Wound & 82 years & This study \\
\hline NCS14 & VI & $365(98)$ & $83(66)$ & Uterus & 33 years & This study \\
\hline NT6 & VI & $305(21)$ & $248(50)$ & Unknown & Unknown & Wilkinson (1977) \\
\hline NCS15 & VII & $445(95)$ & $140(46)$ & Blood & 34 years & This study \\
\hline 7271 & VII & $105(22)$ & $60(87)$ & Unknown & Unknown & Perch et al. (1979) \\
\hline JM9/9700886 & VIII & $261(126)$ & $219(73)$ & Unknown & Unknown & Wagner et al. (1994) \\
\hline E. coli $\mathrm{DH} 5 \alpha$ & NA & $34(2)$ & $39(28)$ & NA & NA & NA \\
\hline
\end{tabular}

* CSF, cerebrospinal fluid.

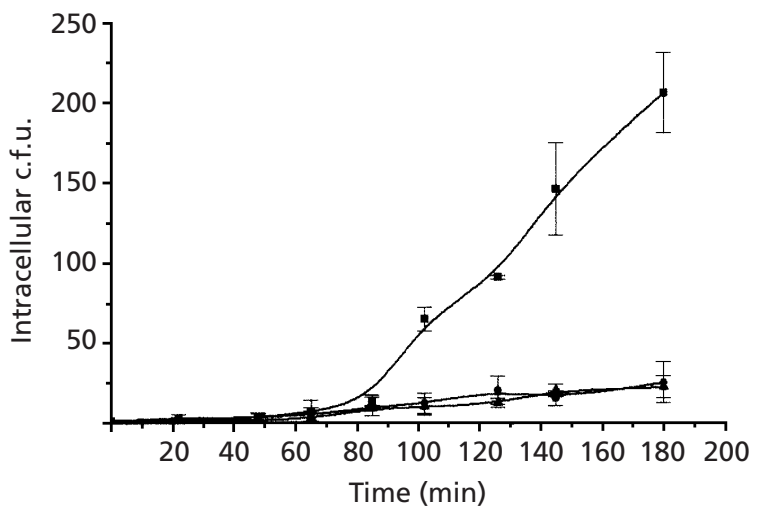

Fig. 1. Intracellular GBS (c.f.u. \pm SD) recovered from HeLa cells and MRC-5 cells infected up to $180 \mathrm{~min}$. GBS were grown overnight, after which the concentration was adjusted to 0.5 McFarland. For HeLa cells pretreated with cytochalasin D, $1.0 \mu \mathrm{g}$ cytochalasin $\mathrm{D} \mathrm{ml} \mathrm{m}^{-1}$ was added $1 \mathrm{~h}$ prior to the addition of NCS13. One hundred microlitres of a 1:100 dilution was then added to the monolayer of HeLa cells or MRC-5 cells and an invasion assay performed. Wells were treated with trypsin and plated onto SBA at the time points indicated. HeLa cells; MRC-5 cells; $\mathbf{\Delta}$, HeLa cells pretreated with cytochalasin D.

HeLa cell monolayers were exposed to NCS13 and removed at $1 \mathrm{~h}$ time points. These were then fixed and observed using SEM. The electron micrographs showed that very little binding of NCS13 to the HeLa cell surface occurred in the first hour (Fig. 2a). However, after $2 \mathrm{~h}$, numerous chains of NCS13 began to appear bound to the HeLa cell surface, and this trend continued to increase, presumably through increased binding and possibly multiplication of bacteria already on the cell surface (Fig. 2b). At $4 \mathrm{~h}$, the nucleus of the cell started to bulge noticeably (Fig. 2d), and at $5 \mathrm{~h}$, the number of chains of NCS13 on the HeLa cell became extensive, with very little of the HeLa cell surface visible (Fig. 2e). After 6 h, the HeLa cell was destroyed, and almost all of the monolayer lifted off (Figs $2 \mathrm{f}$ and $3 \mathrm{a}$ ). The SEM appearance of the destroyed HeLa cell at $6 \mathrm{~h}$ post-GBS exposure suggested that the cell was shrunken by approximately half and, in some instances, ruptured (Fig. 2f). It had been previously reported that GBS induced no morphological changes in A549 epithelial cells up to $8 \mathrm{~h}$ and in HEp-2 cells up to $48 \mathrm{~h}$ (Rubens et al., 1992; Valentin-Weigand et al., 1997). However, in these assays, the GBS were allowed to invade for $2 \mathrm{~h}$, and then antibiotics were added for $8 \mathrm{~h}$ (A549) and $48 \mathrm{~h}$ (HEp-2); therefore, all extracellular GBS were killed (Rubens et al., 1992; Valentin-Weigand et al., 1997). In our assay, no antibiotics were added, thereby allowing extracellular GBS to interact continually with the HeLa cell surface over the entire period.

To determine whether the death of the HeLa cells after $6 \mathrm{~h}$ was due to the direct interaction of GBS with the HeLa cell or was due to some factor secreted by the bacteria, a transwell membrane assay was used. HeLa cells were grown on plastic coverslips in the well, and bacteria were either added to the membrane separating bacteria and HeLa cells or added directly to the HeLa cell monolayer. Only the monolayer that was directly exposed to NCS13 was destroyed after $6 \mathrm{~h}$ (Fig. 3a). The monolayer that was separated from the GBS by a 

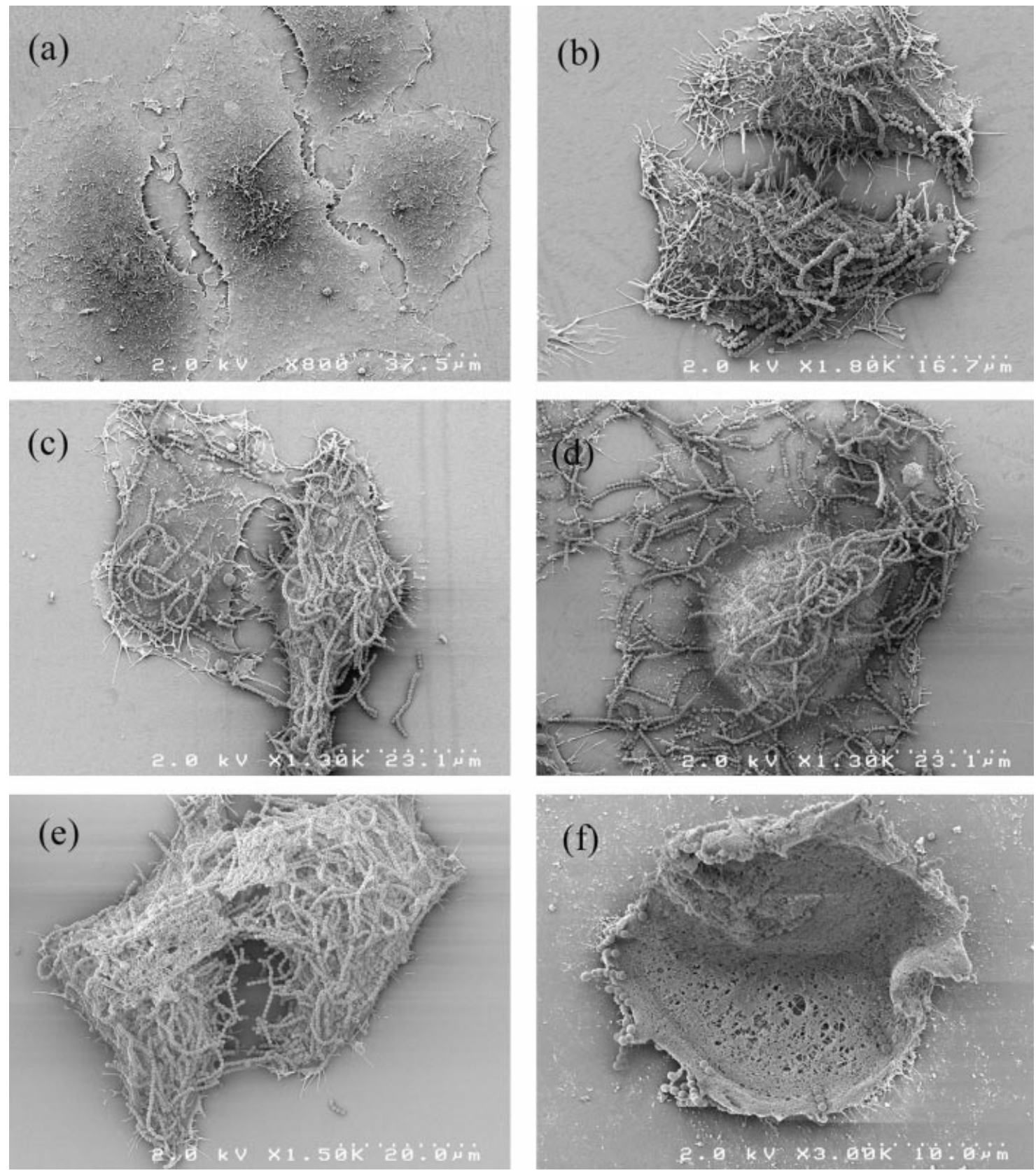

Fig. 2. Time-course assay. NCS13 was added to confluent monolayers of HeLa cells grown on coverslips and allowed to interact for the times indicated below. Coverslips were washed three times with PBS and prepared for, and examined by, SEM: (a) $1 \mathrm{~h}$ post-infection; (b) $2 \mathrm{~h}$ post-infection; (c) $3 \mathrm{~h}$ post-infection; (d) $4 \mathrm{~h}$ post-infection; (e) $5 \mathrm{~h}$ post-infection; ( $\mathrm{f}$ ) $6 \mathrm{~h}$ post-infection.

membrane remained intact after $6 \mathrm{~h}$, indicating that the destruction was not caused by a component secreted by GBS able to travel through a transwell filter (Fig. 3b). To determine whether HeLa cell destruction was due to an increase in the acidity of the medium, fresh tissueculture medium was added after $3 \mathrm{~h}$, and the incubation continued for an additional $3 \mathrm{~h}$. The HeLa cells were still destroyed, indicating that fresh medium at neutral $\mathrm{pH}$ failed to prevent this activity (Fig. 3c).
A suggested mechanism for epithelial cell destruction is an increase in the number of GBS invading the HeLa cell, which would correlate with the increase in number of GBS bound. It is possible that the increase in intracellular GBS physically reaches a limit, and the HeLa cell bursts. An alternative possibility is the activity of the GBS surface associated $\beta$-haemolysin (Marchlewicz \& Duncan, 1980; Platt, 1995). Nizet et al. (1996) have reported that the GBS $\beta$-haemolysin can 

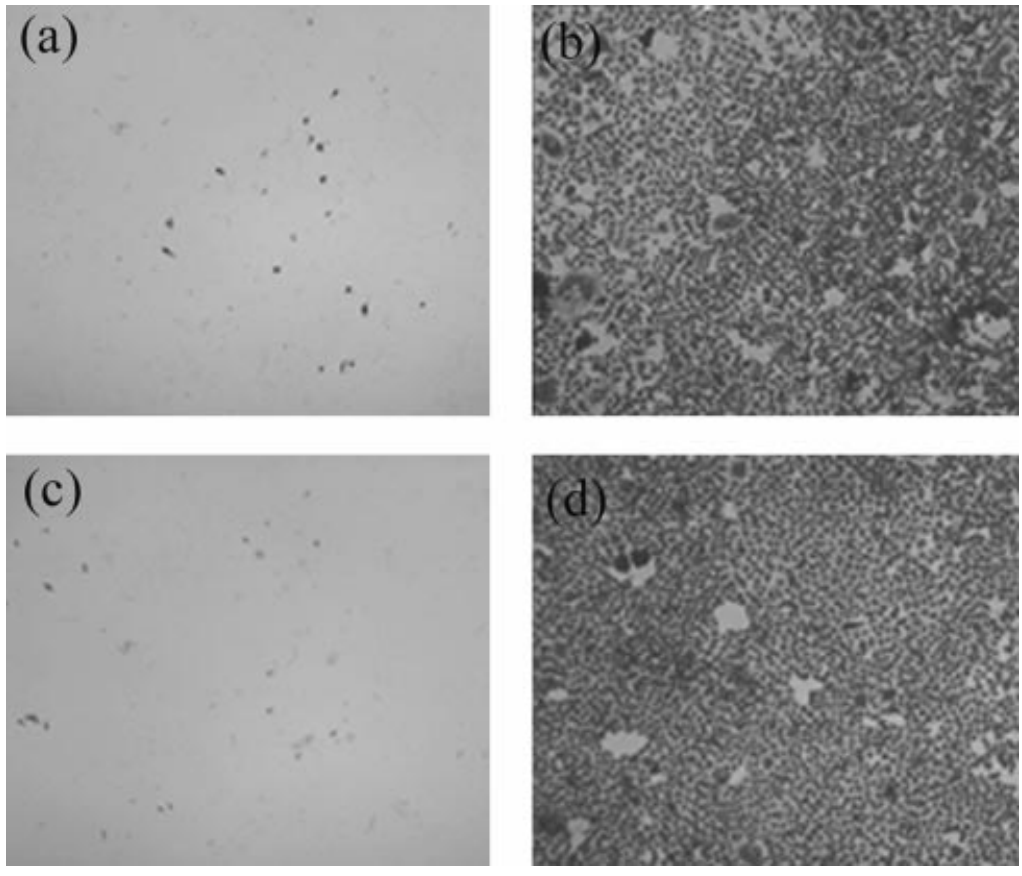

Fig. 3. Comparison of the effect of NCS13 contacting and not contacting the HeLa cell surface after $6 \mathrm{~h}$ post-infection. HeLa cells were grown on plastic coverslips in a transwell plate to confluency. (a) GBS placed directly in the well with the HeLa cell monolayer. No membrane present. (b) GBS placed in an upper well separated from HeLa cells by a $0.4 \mu \mathrm{m}$ membrane. (c) HeLa cells exposed to GBS for $3 \mathrm{~h}$ after which the cell culture media were removed and fresh media added. The incubation was then extended for a further $3 \mathrm{~h}$. (d) HeLa cells alone, no bacteria. cause injury to lung epithelial cells, so it is possible that this haemolysin is destroying the HeLa cells after an extended period of contact with NCS13.

\section{GBS interactions with MRC- 5 cells}

Rubens et al. (1991) and Gibson et al. (1993) had previously reported the presence of GBS inside membrane-bound vacuoles within fibroblasts, so we wanted to determine how invasive the collection of GBS strains in Table 1 would be against the fibroblastic cell line MRC-5. Table 1 shows the mean c.f.u. $( \pm S D)$ for the invasion of MRC-5 cells by GBS strains. All GBS strains invaded MRC-5 cells to a similar low level, and no GBS strain invaded MRC-5 cells at the level NCS13 invaded HeLa cells. Since the majority of GBS strains invaded MRC- 5 cells less than they invaded HeLa cells, this suggested that there are important differences between HeLa cells and MRC-5 cells that affect the ability of GBS to invade. To be consistent in our study and allow direct comparisons with HeLa cells, we chose NCS13 for a further analysis of GBS-MRC-5 cell interactions. A quantitative invasion assay of NCS13 against MRC-5 cells showed that, after a $180 \mathrm{~min}$ exposure to NCS13, the invasion rate was very low in comparison to HeLa cells (Fig. 1). To determine whether the preventative step in NCS13 invasion of MRC-5 cells was the initial binding of the bacteria to the fibroblast surface, NCS13 was allowed to bind to the surface of MRC-5 cells grown on glass coverslips for $2 \mathrm{~h}$. Bacteria bound to the surface were visualized via fluorescent confocal microscopy using anti-GBS rabbit antibody followed by rhodamine-labelled goat anti-rabbit antibody. Confocal imaging showed low numbers of NCS13 bound to the MRC-5 cell surface, suggesting that the poor invasion was due to a lack of binding (Fig. 4a).
SEM was used to observe the GBS-MRC-5 cell interaction at a higher magnification. Fig. 4(b) shows minimal binding of NCS13 to the MRC-5 cell surface, suggesting that this fibroblastic cell line does not possess receptors for GBS. In comparison, the binding of NCS13 to HeLa cells, as visualized using confocal microscopy and SEM, found that the cocci bound in large numbers to the surface of the HeLa cell, suggesting that, in contrast to MRC-5 cells, HeLa cells do possess receptors for GBS (Figs $2 \mathrm{~b}$ and $5 \mathrm{a}$ ).

\section{Fibronectin and binding of GBS to HeLa and MRC-5 cells}

Others have reported that GBS can bind to immobilized fibronectin, so we wanted to visualize any fibronectin on the surface of the HeLa cell that NCS13 could be binding (Beckmann et al., 2002; Cheng et al., 2002; Tamura \& Rubens, 1995; Tamura et al., 2002). To visualize surface-exposed fibronectin, a rabbit anti-human fibronectin polyclonal antibody followed by an anti-rabbit FITC conjugate was used (FITC-fibronectin assay). Fluorescent imaging showed that no fibronectin was visible on the HeLa cell surface using this polyclonal antibody at a concentration of $1: 400$ (Fig. 5b). This is in contrast to MRC-5 cells, which demonstrated fibronectin over the entire cell surface (Fig. 5c). To further compare levels of fibronectin on the surfaces of MRC-5 cells vs HeLa cells, an EIA was done using the antifibronectin antibody. At a 1:400 dilution of antifibronectin antibody, there was $2 \cdot 7$-fold more fibronectin present on MRC-5 cells vs HeLa cells $\left(A_{405} 0.51\right.$ for MRC-5 vs $0 \cdot 19$ for HeLa cells). While some fibronectin is present on HeLa cells, as determined by an EIA, it is not at the level present on MRC-5 cells and is at a level low enough not to be visible in the FITC-fibronectin 

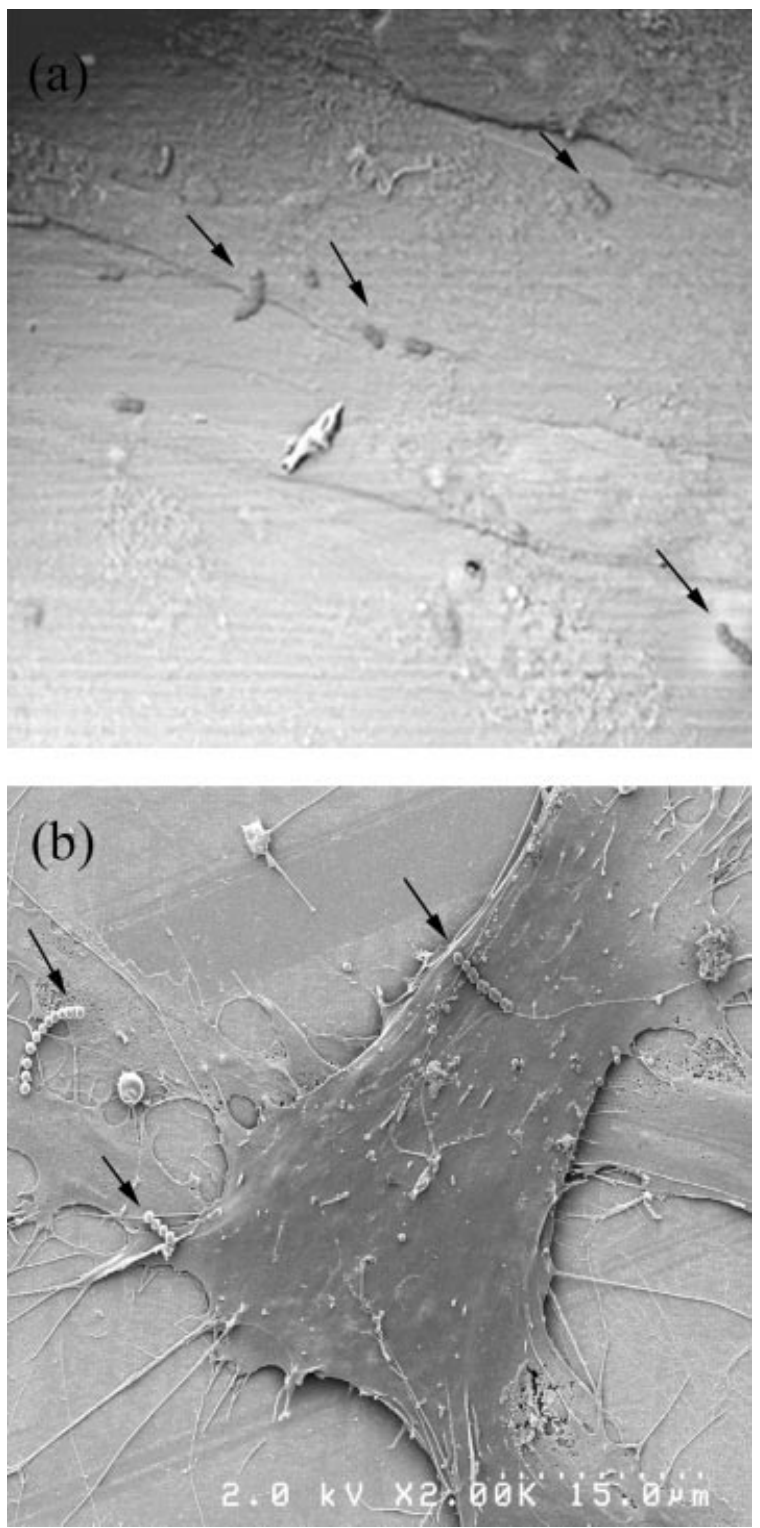

Fig. 4. Binding of NCS13 to MRC- 5 cells. Approximately $1.5 \times 10^{6}$ GBS were added to a confluent monolayer of MRC- 5 cells and incubated at $37^{\circ} \mathrm{C}$ for $2 \mathrm{~h}$. The monolayer was then washed three times with PBS and bound NCS13 visualized using antiGBS antibodies or by SEM. (a) Confocal fluorescent/phasecontrast image of MRC-5 cells and NCS13. (b) SEM micrograph of MRC- 5 cells and NCS13. Arrows in both images indicate the locations of NCS13 on the MRC-5 cell surface. Note the differences in numbers of NCS13 bound to MRC- 5 cells in comparison to HeLa cells in Fig. 2(b) at $2 \mathrm{~h}$.

assay. The finding that NCS13 binds extremely well to HeLa cells and not in any appreciable extent to MRC-5 cells suggests that NCS13 may not bind to fibronectin in the context of the host-cell membrane for these cell lines.

The finding that NCS13 does not bind to a cell line containing large amounts of fibronectin, suggesting that fibronectin is not acting as a receptor in this cell line, is somewhat contradictory to the findings of others. Work
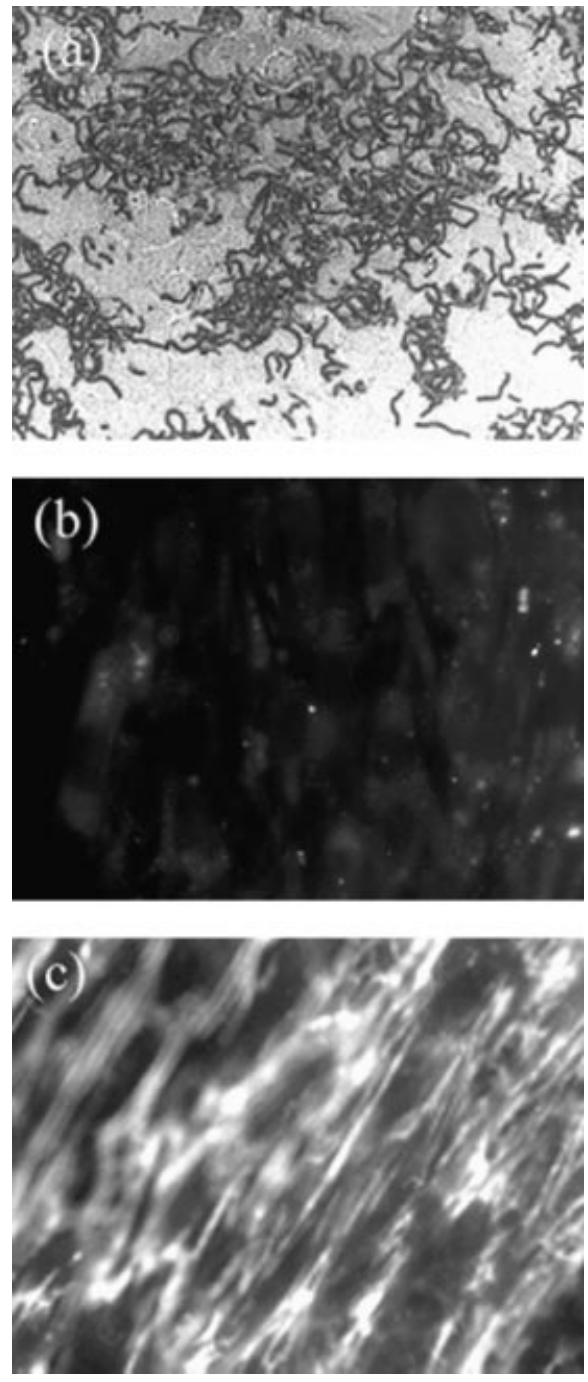

Fig. 5. (a) Confocal laser scanning microscopy of GBS bound to HeLa cells. GBS were added to HeLa cell monolayers grown on coverslips and allowed to bind for $2 \mathrm{~h}$. Rabbit anti-GBS antibody was added followed by rhodamine-labelled antirabbit antibody. Cells were then examined using confocal microscopy. (b) HeLa cells treated with rabbit anti-fibronectin antibody followed by treatment with anti-rabbit FITC conjugate. (c) MRC-5 cells treated as in (b).

by Cheng et al. (2002) demonstrated that the GBS strain 090R invaded HEp-2 and A549 cells, and when 090R was mutated in the $s c p B$ gene (a GBS gene that encodes the fibronectin-binding protein $\mathrm{SCPB}$ ), levels of binding and invasion were reduced. Further work by Tamura $e t$ al. (2002) showed that the GBS strain COH1, when mutated by $\operatorname{Tn} 917$ in the $g \ln Q$ gene, failed to bind to immobilized fibronectin, in comparison to the wild-type $\mathrm{COH} 1$, and exhibited decreased adherence and invasion of A549 cells, a cell line also containing fibronectin on its surface.

Based on these reports and others that have shown that GBS binds to immobilized fibronectin, we expected NCS13 to bind to the fibronectin-containing cell line 

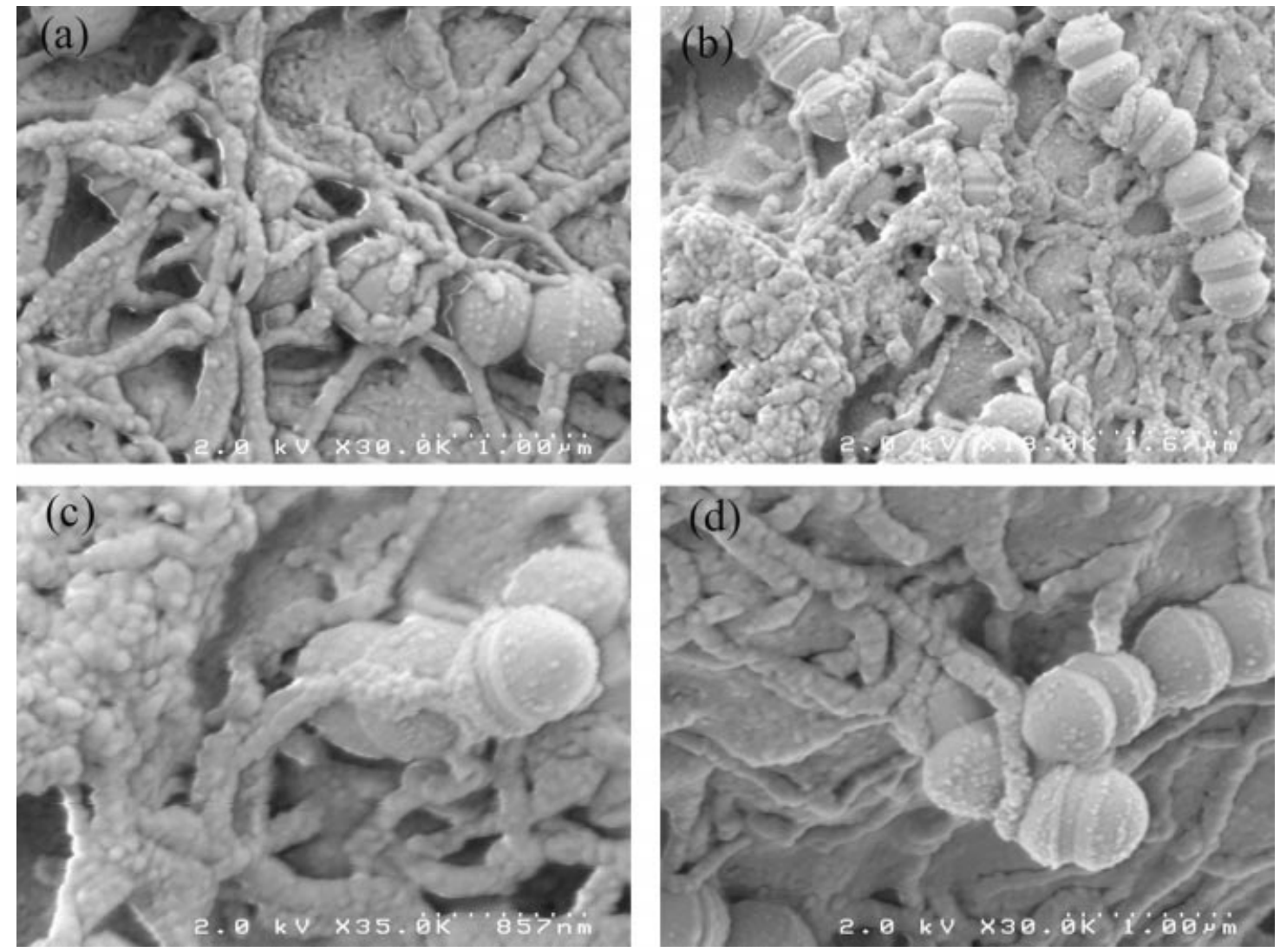

Fig. 6. SEM micrographs of HeLa cells and NCS13. (a, b) Chains of NCS13 with microvilli covering the bacteria. (c, d) NCS13 entering the HeLa cell. Microvilli appear to be aiding this process.

MRC-5 (Beckmann et al., 2002; Cheng et al., 2002; Tamura \& Rubens, 1995; Tamura et al., 2002). A possible reason why we did not observe significant binding of NCS13 to MRC-5 cells may be that the cells have a different isoform of fibronectin. Fibroblastic cells such as MRC-5 cells may contain a form of fibronectin that does not permit GBS receptorfibronectin interactions to occur, whereas the small amount of fibronectin on HeLa cells (epithelial cells) is an isoform that has a higher affinity for NCS13. Another possibility is that the previous investigators used different GBS strains to those used in this study. Tamura \& Rubens (1995) examined the ability of nine strains of GBS to bind to fibronectin immobilized on a polystyrene-coated surface. The percentage of GBS bound to fibronectin in this manner varied widely ranging from 4 to $60 \%$ of the input, depending on the strain used. It is therefore possible that strains used in other studies have a greater ability to bind fibronectin in comparison to the strains used in this study. However, this seems unlikely as we examined 18 different strains from different sources, and all did not invade MRC-5 cells very well. Recently, Spellerberg et al. (2002) explored the binding of GBS to a variety of extracellular matrix proteins. It was observed that GBS did not adhere to fibronectin as well as fibrinogen, thrombo- spondin and vitronectin, and only bound fibronectin slightly better than laminin (Spellerberg et al., 2002).

These observations suggest that GBS may be using fibronectin as a receptor in some cell lines, but the bacterium clearly has the ability to utilize other host-cell structures to allow it to bind.

\section{Electron microscopic analysis of NCS13 binding to HeLa cells}

The binding of NCS13 to HeLa cells was examined in greater detail using SEM. A close examination of Fig. $6(\mathrm{a}, \mathrm{b})$ shows numerous HeLa-cell-derived microvilli in contact with the chains. Microvilli can be seen wrapped around the chains in both the SEM (Fig. 6a, b) and TEM (Fig. 7a, b) electron micrographs.

The role of the microvilli in GBS binding and invasion is unclear. The electron micrographs suggest that microvilli entwine the chains of bacteria followed by eventual entry into the cell (Fig. 7c, d). HeLa cell entry appears to occur in a polar fashion, as previously suggested by Valentin-Weigand et al. (1997) for GBS entry into HEp-2 cells, with the exception that the involvement of HeLa cell microvilli seems to be more prominent than in HEp-2 cells (Fig. 6c, d). 


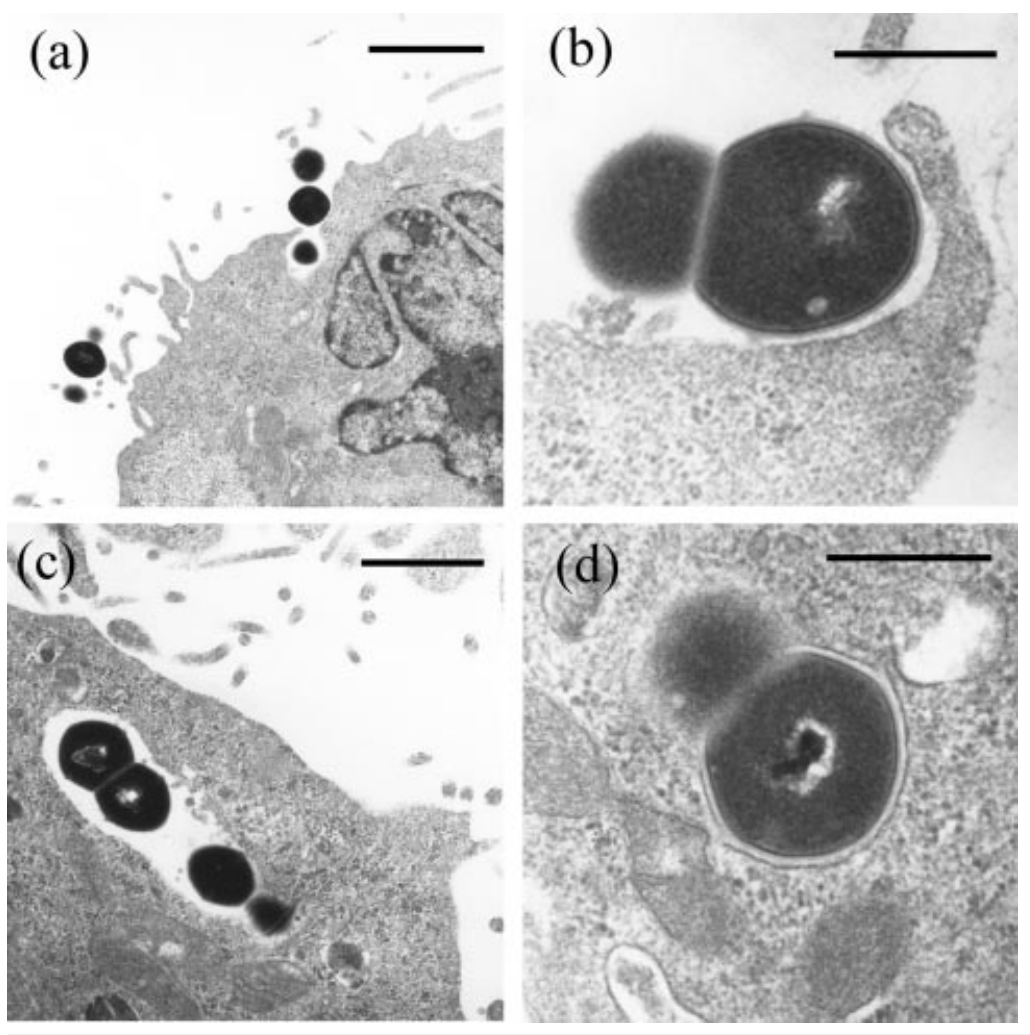

Fig. 7. TEM micrographs of HeLa cells and NCS13. (a) Chains of NCS13 attached to the HeLa cell surface. Bar, $2 \mu \mathrm{m}$. (b) NCS13 bound to a HeLa cell microvillus. Bar, $500 \mathrm{~nm}$. (c, d) NCS13 inside HeLa cell-membranebound compartments. Bar (c), $1 \mu \mathrm{m}$. Bar (d), $500 \mathrm{~nm}$.
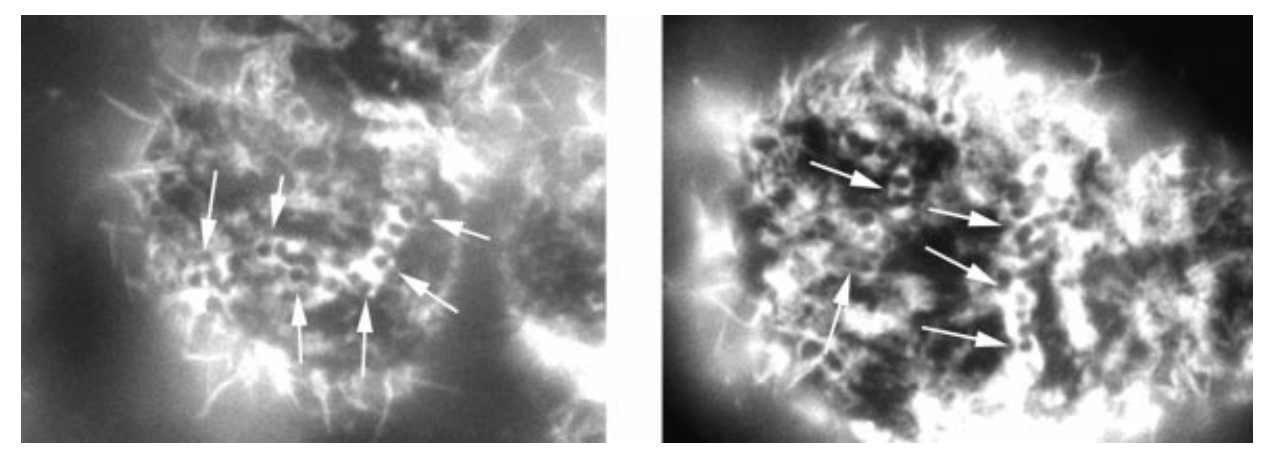

Fig. 8. HeLa cell actin recruited to the site of NCS13 attachment. HeLa cells were infected with NCS13 for $1 \mathrm{~h}$, fixed, permeabilized and stained with FITC-labelled phalloidin. Fluorescent images were visualized by fluorescent microscopy as described in the Methods. Chains of streptococci are outlined by fluorescently stained actin indicated by the arrows.

\section{Involvement of HeLa cell actin during NCS13 binding and invasion}

The observation that HeLa cell microvilli interact intimately with GBS, and the knowledge that one of the major components of microvilli is an actin cytoskeleton, prompted us to explore the role of the actin cytoskeleton more closely. HeLa cells exposed to NCS13 were stained with FITC-labelled phalloidin to determine whether cellular actin is recruited to the site of GBS binding. Fig. $8(\mathrm{a}, \mathrm{b})$ shows actin at the site of GBS cocci binding to the HeLa cell surface, suggesting that cellular actin is recruited to the site of GBS binding. This finding was not completely unexpected, as involvement of host-cell actin in bacterial invasion is a theme demonstrated by a number of bacterial pathogens, most recently group A streptococci (Ozeri et al., 2001). Ozeri et al. (2001) demonstrated the recruitment of actin to the site of group A streptococcal binding as well as various other host-cell cytoplasmic components. The image of hostcell actin recruitment to the site of binding by NCS13 is similar to that seen for the group A streptococci, suggesting that similar binding and invasion mechanisms may be used by GBS (Fig. 8).

Previous investigators have found that GBS invasion of eukaryotic cells can be prevented by pre-treatment with cytochalasin D (Gibson et al., 1993; Nizet et al., 1997; Rubens et al., 1992). Cytochalasin D is known to be a potent inhibitor of actin polymerization. Exposure 

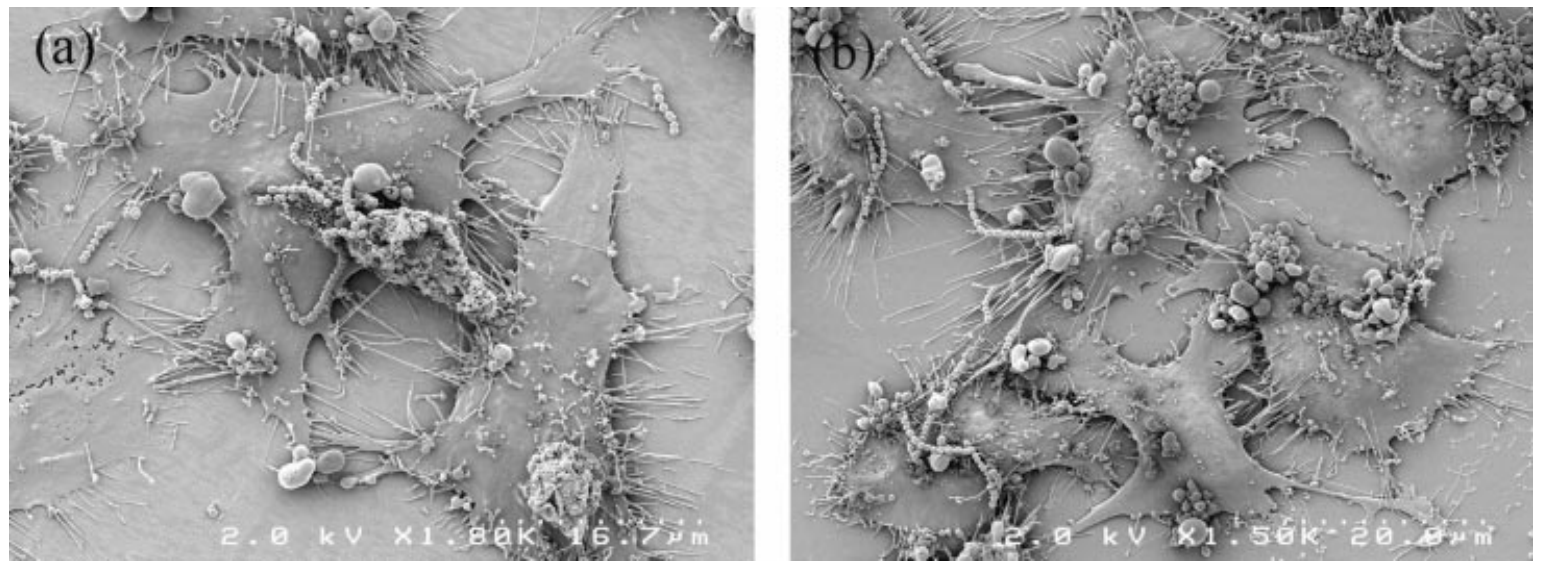

Fig. 9. SEM micrographs of NCS13 and HeLa cells treated with cytochalasin D. (a) HeLa cells exposed to $1.0 \mu g$ cytochalasin $\mathrm{D} \mathrm{ml}^{-1}$ for $1 \mathrm{~h}$ and then exposed to NCS13 for $2 \mathrm{~h}$. The number of NCS13 is reduced in comparison to Fig. 2(b) but not completely negated. (b) NCS13 and HeLa cells treated with $1.0 \mu \mathrm{g}$ cytochalasin D ml ${ }^{-1} 1 \mathrm{~h}$ after NCS13 was added to the HeLa cells. The number of NCS13 bound to the HeLa cell is similar to that in (a).

of HeLa cells to $1 \cdot 0 \mu \mathrm{g}$ cytochalasin $\mathrm{D} \mathrm{ml}^{-1}$ for $1 \mathrm{~h}$ followed by a $3 \mathrm{~h}$ exposure to NCS13 resulted in very low numbers of GBS invading HeLa cells, similar to that seen for MRC-5 cells (Fig. 1). These results reinforce the evidence for involvement of host-cell actin during invasion of host cells by GBS (Gibson et al., 1993; Nizet et al., 1997; Rubens et al., 1992).

To visually examine the effect of cytochalasin $\mathrm{D}$ on the NCS13 HeLa cell interaction, SEM was used. Fig. 9(a, b) shows that the cytochalasin D-treated HeLa cells had lost the short microvilli seen on the surface of untreated HeLa cells and that these were replaced by a smooth cell surface and large protrusions of cellular blebs. Besides the cellular changes seen in the HeLa cells, the binding of NCS13 to cytochalasin D-pretreated cells was reduced in comparison to untreated HeLa cells (Fig. 9a, b). This was also seen in HeLa cells first exposed to NCS13 and then treated with cytochalasin D (Fig. 9c, d), suggesting that cytochalasin D reduces GBS binding to HeLa cells but does not completely inhibit binding. The finding that binding is not completely inhibited may suggest that the GBS receptor(s) are independent of the actin cytoskeleton during the initial binding of GBS to the host-cell surface.

\section{Phosphatidylinositol 3-kinase (PI 3-kinase) involvement in GBS invasion of HeLa cells}

Previous experiments indicating that host-cell actin was recruited to the site of GBS attached and that internalization was inhibited by cytochalasin D suggested involvement of host-cell signalling proteins. One such signalling protein implicated in actin polymerization is PI 3-kinase. Wortmannin at nanomolar concentrations is a potent inhibitor of PI 3-kinase. Increasing concentrations of wortmannin reduced the number of c.f.u. internalized over a $2 \mathrm{~h}$ period. At $2 \mathrm{nM}$, wortmannin reduced entry of GBS into HeLa cells by $8.8 \%$, at $20 \mathrm{nM}$ by $56.3 \%$, at $200 \mathrm{nM}$ by $89.7 \%$ and at
$2 \mu \mathrm{M}$ by $97 \%$. This reduction in GBS internalization by wortmannin suggests that PI 3-kinase does play a role in invasion of HeLa cells by GBS.

\section{Concluding remarks}

In summary, we have shown that GBS are able to destroy HeLa cells after a $6 \mathrm{~h}$ incubation and that this cell destruction can occur only by direct GBS-HeLa cell contact. GBS do not bind and invade MRC-5 cells (a cell line containing large amounts of fibronectin on its surface) to the same level as HeLa cells (a cell line containing a small amount of fibronectin on its cell surface in comparison to MRC-5 cells), suggesting that other host-cell receptors besides fibronectin may also have a role in GBS-host-cell interactions. Once GBS are bound to HeLa cells, HeLa cell microvilli entwine the bacteria, which enter the HeLa cell in a polar fashion. Host-cell cytoskeletal actin is involved as this process is disrupted by cytochalasin $\mathrm{D}$, and recruitment of actin is visible at the site of adherent chains of GBS on the HeLa cell. Also, the host-cell signalling enzyme, PI 3-kinase, is involved in the GBS internalization event as the event can be inhibited by wortmannin.

\section{ACKNOWLEDGEMENTS}

This work was supported in part by University Hospital Foundation/Alberta Health Sciences Research Institute grant and a Children's Health Foundation of Northern Alberta grant.

We thank Glen D. Armstrong for critical review of the manuscript.

\section{REFERENCES}

Allardice, J. G., Baskett, T. F., Seshia, M. M., Bowman, N. \& Malazdrewicz, R. (1982). Perinatal group B streptococcal colonization and infection. Am J Obstet Gynecol 142, 617-620.

Anthony, B., Eisenstadt, R., Carter, J., Kim, K. \& Hobel, C. (1981). 
Genital and intestinal carriage of group B streptococci during pregnancy. J Infect Dis 143, 761-766.

Beckmann, C., Waggoner, J. D., Harris, T. O., Tamura, G. S. \& Rubens, C. E. (2002). Identification of novel adhesins from group B streptococci by use of phage display reveals that C5a peptidase mediates fibronectin binding. Infect Immun 70, 2869-2876.

Campbell, J. R., Hillier, S. L., Krohn, M. A., Ferrieri, P., Zaleznik, D. F. \& Baker, C. J. (2000). Group B streptococcal colonization and serotype-specific immunity in pregnant women at delivery. Obstet Gynecol 96, 498-503.

Cheng, Q., Stafslien, S., Purushothaman, S. P. \& Cleary, P. (2002). The group B streptococcal C5a peptidase is both a specific protease and an invasin. Infect Immun 70, 2408-2413.

Edwards, M. \& Baker, C. (1995). Streptococcus agalactiae (Group B Streptococcus). In Principles and Practices of Infectious Diseases, pp. 2156-2167. Edited by G. Mandell. Philadelphia, PA: Churchill Livingstone.

Farley, M., Harvey, R., Stull, T., Smith, J., Schuchat, A., Wenger, J. \& Stephens, D. (1993). A population-based assessment of invasive disease due to group B Streptococcus in nonpregnant adults. N Engl J Med 328, 1807-1811.

Gibson, R., Lee, M., Soderland, C., Chi, E. Y. \& Rubens, C. E. (1993). Group B streptococci invade endothelial cells: type III capsular polysaccharide attenuates invasion. Infect Immun 61, 478-485.

Hulse, M., Smith, S., Chi, E. Y., Pham, A. \& Rubens, C. E. (1993). Effect of type III group B streptococcal capsular polysaccharide on invasion of respiratory epithelial cells. Infect Immun 61, 4835-4841.

Kallman, J. \& Kihlstrom, E. (1997). Penetration of Group B streptococci through polarized Madin-Darby canine kidney cells. Pediatr Res 42, 799-804.

Knutton, S., Baldwin, T., Williams, P. H. \& McNeish, A. S. (1989). Actin accumulation at sites of bacterial adhesion to tissue culture cells: basis of a new diagnostic test for enteropathogenic and enterohemorrhagic Escherichia coli. Infect Immun 57, 1290-1298.

Lalonde, M., Segura, M., Lacoutre, S. \& Gottschalk, M. (2000). Interactions between Streptococcus suis serotype 2 and different epithelial cell lines. Microbiology 146, 1913-1921.

Marchlewicz, B. A. \& Duncan, J. L. (1980). Properties of a hemolysin produced by group B streptococci. Infect Immun 30, 805-813.

Nizet, V., Gibson, R., Chi, E. Y., Framson, P., Hulse, M. \& Rubens, C. E. (1996). Group B streptococcal $\beta$-hemolysin expression is associated with injury of lung epithelial cells. Infect Immun 64, 3818-3826.

Nizet, V., Kim, K. S., Stins, M., Jonas, M., Chi, E. Y., Nguyen, D. \& Rubens, C. E. (1997). Invasion of brain microvascular endothelial cells by group B streptococci. Infect Immun 65, 5074-5081.

Ozeri, V., Rosenshine, I., Ben-ZeEv, A., Bokoch, G. M., Jou, T. \& Hanski, E. (2001). De novo formation of focal complex-like structures in host cells by invading streptococci. Mol Microbiol 41, 561-573.

Perch, B., Kjems, E. \& Henrichsen, J. (1979). New seroytpes of group B streptococci isolated from human sources. J Clin Microbiol 10, 109-110.

Platt, M. W. (1995). In vivo hemolytic activity of group B Streptococcus is dependent on erythrocyte-bacteria contact and independent of a carrier molecule. Curr Microbiol 31, 5-9.

Rubens, C. E., Raff, H. V., Jackson, J. C., Chi, E. Y., Bielitzki, J. T. \& Hillier, S. L. (1991). Pathophysiology and histopathology of group
B streptococcal sepsis in Macaca nemestrina primates induced after intraamniotic inoculation: evidence for bacterial cellular invasion. J Infect Dis 164, 320-330.

Rubens, C. E., Smith, S., Hulse, M., Chi, E. Y. \& van Belle, G. (1992). Respiratory epithelial cell invasion by group B streptococci. Infect Immun 60, 5157-5163.

Schuchat, A., Oxtoby, M., Cochi, S., Sikes, R. K., Hightower, A., Plikaytis, B. D. \& Broome, C. V. (1990). Population-based risk factors for neonatal group B streptococcal disease: results of a cohort study in metropolitan Atlanta. J Infect Dis 162, 672-677.

Schuchat, A., Deaver-Robinson, K., Plikaytis, B. D., Zangwell, K. M., Mohle-Boetani, J. \& Wenger, J. D. (1994). Multistate casecontrol study of maternal risk factors for neonatal group B streptococcal disease. The Active Surveillance Study Group. Pediatr Infect Dis J 13, 623-629.

Spellerberg, B., Rozdzinski, E., Martin, S., Weber-Heynemann, J., Schnitzler, N., Lutticken, R. \& Podbielski, A. (1999). Lmb, a protein with similarities to the Lra1 adhesion family, mediates attachment of Streptococcus agalactiae to human laminin. Infect Immun 67, 871-878.

Spellerberg, B., Rozdzinski, E., Martin, S., Weber-Heyneman, J. \& Luticken, R. (2002). $r g f$ encodes a novel two-component signal transduction system of Streptococcus agalactiae. Infect Immun 70, 2434-2440.

Tamura, G. S. \& Rubens, C. E. (1994). Host-bacterial interactions in the pathogenesis of group B streptococcal infections. Curr Opin Infect Dis 7, 317-322.

Tamura, G. S. \& Rubens, C. E. (1995). Group B streptococci adhere to a variant of fibronectin attached to a solid phase. Mol Microbiol 15, 581-589.

Tamura, G. S. \& Nittayajarn, A. (2000). Group B streptococci and other Gram-positive cocci bind to cytokeratin 8. Infect Immun 68, 2129-2134.

Tamura, G. S., Nittayajain, A. \& Schoentag, D. L. (2002). A glutamine transport gene, $g \ln Q$, is required for fibronectin adherence and virulence of group B streptococci. Infect Immun 70, 2877-2885.

Tyrrell, G. J., Senzilet, L. D., Spika, J. S., Kertesz, D. A., Alagaratnam, M., Lovgren, M., Talbot, J. A. \& the Sentinel Health Unit Surveillance System Site Coordinators (2000). Invasive disease due to group B streptococcal infection in adults: results from a Canadian, population-based, active laboratory surveillance study-1996. J Infect Dis 182, 168-173.

Valentin-Weigand, P. \& Chhatwal, G. S. (1995). Correlation of epithelial cell invasiveness of group B streptococci with clinical source of isolation. Microb Pathog 19, 83-91.

Valentin-Weigand, P., Benkel, P., Rhode, M. \& Chhatwal, G. S. (1996). Entry and intracellular survival of group B streptococci in J774 macrophages. Infect Immun 64, 2467-2473.

Valentin-Weigand, P., Jungnitz, H., Zock, A., Rhode, M. \& Chhatwal, G. S. (1997). Characterization of group B streptococcal invasion in HEp-2 epithelial cells. FEMS Microbiol Lett 147, 69-74.

Wagner, M., Murai, T., Wagner, B., Gunther, E. \& Jelinkova, J. (1994). JM9 strains, a new type of group B streptococci from Japan. Zentbl Bakteriol 280, 488-496.

Wilkinson, H. W. (1997). Nontypable group B streptococci isolated from human sources. J Clin Microbiol 6, 183-184.

Received 20 May 2002; revised 15 August 2002; accepted 5 September 2002. 